\title{
Resenhas
}





\section{Putin e a inserção internacional da Rússia}

Lenina Pomeranz ${ }^{I}$

$\mathrm{O}_{\mathrm{d}}^{\mathrm{s}}$ DOIS LIVROS referenciados, surgidos no final de 2018, têm como centro, cada um a seu modo, a figura de Putin como o mandatário da Federação da Rússia. A afirmação de "cada um a seu modo" tem sua razão de ser no objetivo mirado por cada um dos autores. Esta resenha busca distingui-las, tendo porém como foco a política exterior do país, conduzida por Putin.

Tony Wood, autor do primeiro, é membro do Conselho Editorial da New Left Review, tendo seus textos aparecido na London Review of Books, no Guardian, em $n+l$ e na Nation, de acordo com sua apresentação no livro. Segundo afirma, seu objetivo é mostrar que a excessiva concentração da mídia internacional na figura de Putin obscurece qualquer real compreensão do país, devendo o Ocidente eliminar essa obsessão e olhar o país para além das paredes do Kremlin. A própria política externa conduzida por Putin tem que ser analisada a partir dessa compreensão, ou seja, entendida menos como resultado de deliberação individual do presidente e mais como resultado da natureza do sistema por ele conduzido. Dessa forma, o objetivo do livro é o de traçar um quadro da Rússia contemporânea que ultrapassa os cabeçalhos sobre o seu presidente.

O que não o impede de dedicar todo o primeiro capítulo do livro à figura de Putin e ao sistema por ele presidido ("The man and the system"). Um segundo capítulo é dedicado às figuras dominantes desse sistema, analisando o que entende como a simbiose entre o estado e os negócios e sua evolução desde sua origem, ainda no sistema soviético com a chamada nomenclatura. Ambos os capítulos são bastante informativos, mas fogem ao objetivo dessa referência que, como dito acima, consiste em analisar a política externa da Rússia conduzida por Putin. É no capítulo três que surge a análise detalhada que leva o autor à definição da natureza do sistema:

[...] ela decorre da coexistência de duas estruturas sociais, uma em construção sobre as desintegradas ruinas da outra, que deu lugar a um paralelismo do velho com o novo - uma espécie de desenvolvimento social desigual combinado, que teria tornado mais suave a transição capitalista. Além da sobrevivência de partes do sistema de bem-estar soviético, velhas estruturas sociais e maneiras de pensar se mantiveram a despeito de novas estarem emergindo.

Segundo o autor, a situação geopolítica da Rússia atualmente constitui uma versão externa desse paralelismo do velho com o novo entre suas fronteiras: não mais uma superpotência rival dos Estados Unidos, ela ainda não aceita a ideia de tornar-se ator em segundo nível, regional (p.148). Essa posição de status intermediário, associada a várias outras restrições, internas e externas, é que formatará a posição que o país ocupará no mundo no futuro, limitando as escolhas de suas lideranças.

O autor afirma, entretanto, que o seu papel se manterá significativo mesmo em um século que promete sérias mudanças no balanço global de poder. E se propõe a examinar como o país se vê no futu- 
ro e quais os obstáculos e oportunidades que se apresentam no seu caminho. Assim, ele examina, inicialmente, a crescente afirmação do orgulho nacional e uma ressurgência do patriotismo, que se tornaram mais estridentes depois da crise da Ucrânia. Politicamente, esse novo nacionalismo seria predominantemente conservador, no sentido de que se volta para as glórias do passado soviético ou do passado imperial.

Outra versão do nacionalismo volta-se para a Europa fascista e para a tradição de extrema direita. Ambas as versões nacionalistas ganharam algum apoio nos anos 2000, sem que nenhuma delas se tenha tornado dominante ideologicamente. Em seguida avalia historicamente o eurasianismo, afirmando que a sua versão corrente no século XXI foca na Eurásia como uma unidade, vendo-a como fundamentalmente oposta ao Ocidente; o neoeurasianismo seria concernente acima de tudo com a luta contemporânea contra a globalização conduzida pelo Ocidente, que viria impondo ao mundo um cosmopolitismo liberal homogeneizante.

Mas a tese principal do autor sobre as opções geopolíticas da Rússia, por um considerável tempo no futuro, é a de que elas serão definidas por uma serie de restrições, algumas decorrentes da dinâmica interna do país, enquanto outras, mais importantes, emergem no nível global. O caráter mais decisivo de seu papel no mundo atualmente decorre de seu status intermediário.

Grande demais para ser incluída em blocos regionais como a União Europeia e muito independente dos Estados Unidos para ser admitida na OTAN, a Rússia não é mais, entretanto, suficientemente poderosa para formar um polo geopolítico ou econômico próprio. Ela ocupa um a difícil categoria média entre os Estados Unidos hegemônico e uma crescente China, por um lado; e por outro, um conjunto de grandes países, especialmente Brasil e Índia, que estão rapidamente deixando seu status de países em desenvolvimento. (p.156)

Discutindo o que considera a tremenda disparidade de poder e recursos entre a Rússia e o Ocidente, o autor aponta para as suas desiguais capacidades militares. E prossegue em análise em seu todo contrária à adotada por Stephen Cohen, como se verá mais adiante. Segundo ele, o que torna Moscou capaz de constituir uma ameaça militar aos seus vizinhos não é tanto a escala ou a forma de suas armas, como a sua prontidão para usar a força rápida e decisivamente. Mas essa ameaça constituiria uma armadilha mais que uma vantagem; a possibilidade de que Moscou use força contra eles, já levou os vizinhos da Rússia à Otan e deu impulso a uma nova rodada de corrida armamentista para a qual a Rússia ainda é menos equipada que nos tempos soviéticos.

O status intermediário da Rússia seria, em certa medida, um resíduo do papel da URSS como o centro do chamado Segundo Mundo e das décadas de esforço para construir um sistema alternativo ao capitalismo ocidental. A possibilidade de a Rússia liderar um desafio dessa natureza atualmente parece remota, entretanto, para o autor, segundo o qual, mesmo levando em conta a tentacular difusão da influência de Putin, sua capacidade factual de criar resultados políticos teria sido comprovadamente negligenciável ou não existente.

O resto do capítulo é dedicado à discussão da política externa da Rússia: “O 
que a Rússia quer?”. Ela foge, porém, aos limites deste texto, pois demandaria uma atualização bastante ampla do protagonismo político internacional da Rússia e sua análise.

Stephen F. Cohen, autor dos textos publicados no segundo livro referenciado, é professor emérito da Universidade de Columbia, em Nova York, e conhecido estudioso da URSS e da Rússia pós-soviética, tendo vasta obra a respeito da sociedade e da política soviética e russa.

O livro em referência é constituído por textos anteriormente publicados, focados nas relações entre os Estados Unidos e a Rússia. Dirigindo-se a seus leitores, na apresentação do livro, Cohen informa que os textos não foram inicialmente pensados para constituir um livro, tendo sido escolhidos dentre os que foram objeto de transmissões radiofônicas semanais que fez a convite de John Batchelor, condutor de um programa nacional popular de notícias na TV americana. Essas transmissões eram transcritas de imediato na internet, para a revista Nation, na qual Cohen assumiu uma coluna mensal Sovieticus, nos anos 1980. Além do Prólogo, escrito no final de 2018, o livro é composto de quatro partes, com artigos selecionados das cerca de 150 colunas apresentadas na web.

Preocupado com o surgimento de uma nova guerra fria no âmbito das relações entre os Estados Unidos e a Rússia, Cohen identifica um processo de demonização do presidente Putin como centro e foco do seu desenrolar. Daí porque, ao lado dos artigos editados cronologicamente entre os anos 2016 e agosto de 2018, Cohen dedica o prólogo à refutação de sete acusações feitas recorrentemente a Putin na mí- dia americana: 1) desfez a democracia estabelecida pelo presidente Yeltsin; 2) Putin tornou-se um czar autocrático do tipo soviético, com absoluto poder para transformar seus desejos em política; 3) Putin é o líder do Kremlin que reverencia Stalin; 4) Putin criou o sistema econômico cleptocrático pós-soviético; 5) Putin é um canalha da KGB, que ordena regularmente a morte de jornalistas inconvenientes e inimigos pessoais, como chefe de uma máfia estatal; 6) Putin é fascista e supremacista branco; 7) Como líder de política internacional, Putin é excessivamente "agressivo".

Situando-se em posição intermediária entre o espectro de pessoas que só veem o lado bom e as que só veem o lado mau de Putin, seu objetivo declarado ao escrever o prólogo foi fazer "entender pelo menos o que ele não é". Cohen ainda se detém, no Prólogo, em dois outros axiomas sobre o "agressivo Putin". Um afirma que Putin é um líder neossoviético que procura restaurar a URSS às expensas de seus vizinhos, para isso utilizando a afirmação dele de que o colapso da URSS foi a maior catástrofe geopolítica do século XX, como foi para a maioria de russos. Mas, afirma Cohen, que Putin, mantendo-se em parte uma pessoa soviética, declarou em 2010 que "qualquer pessoa que não lamenta a quebra da URSS não tem coração; qualquer pessoa que deseja o seu renascimento não tem cabeça" (aspas do autor).

O outro axioma é o de que Putin sempre foi antiocidental, especificamente antiamericano. Indicando as atitudes de Putin entre a sua posse e o final de 2017 e as respostas que lhe foram dadas, o autor afirma que o líder admitiu ter ilusões inicialmente sobre política ex- 
terna, mas também afirmou que "todos mudam". Em conclusão, Cohen afirma que os temas a que se referiu são recorrentes na avaliação de Putin. Eles constituem um ponto de partida para compreensão da figura do líder, sendo várias as questões que se põem. Qualquer que seja, porém, o enfoque para analisá-las, ele sugere que a avaliação seja balanceada, não para demonizar, não para zombar, não para odiar, mas para entender.

A Parte I do livro é dedicada a palestras que indicam a irrupção da por ele chamada nova guerra fria, envolvendo os anos 2014 e 2015. A Parte II envolve o ano de 2016, e seus textos tratam a retórica das acusações à Rússia em torno da crise na Ucrânia e da guerra na Síria. Dois textos chamam a atenção: i) a expectativa do autor em relação à possibilidade de distensão nas relações entre os Estados Unidos e a Rússia, como se sabe atualmente completamente ilusória, como ele retrata no texto sobre o surgimento de um neomccartismo, com declarações relacionadas à eleição de Donald Trump e as acusações de interferência nela, por parte de Putin; e, ii) a ressurgência de sentimentos pró-Stalin unicamente na era Putin. Como estudioso das questões soviéticas e russas, o autor afirma que a Rússia tem estado profundamente dividida entre o papel histórico de Stalin desde sua morte, em 1953. Mas, sob Putin, o passado stalinista não está novamente sendo censurado, os horrores do passado são amplamente conhecidos na Rússia; nada remotamente semelhante ao stalinismo histórico está presente ou se desenvolvendo na Rússia; Putin não é, em palavras ou ações um stalinista. Ao contrário, graças ao seu apoio foi construído em Moscou um grande e moderno Museu da história do Gulag (sigla que em russo denomina a administração dos campos de trabalho forçado na URSS (Nota da autora deste texto).

A Parte III considera o agravamento da nova guerra fria, tratando essencialmente das recorrentes acusações de conluio Putin-Trump, da oposição na própria Rússia à política de détente de Putin e, novamente do neomccartismo. Cabe, porém, ressaltar, inclusive por oposição às considerações referidas de Wood, o texto em que analisa a expansão da Otan. Essa expansão incluiu duas promessas quebradas: i) a de que em retribuição à concordância da Rússia ao ingresso da Alemanha reunida na Otan, a "aliança não avançaria uma polegada" em direção ao Leste; avançando um pouco os comentários sobre isso, incluídos na Parte IV do livro, cabe assinalar a informação de Cohen, de que em 2018, o Arquivo de Segurança Nacional da Universidade George Washington estabeleceu a verdade histórica, publicando, em 12 de dezembro de 2017, não só um relatório detalhado do que foi prometido a Gorbachev, como os próprios documentos relevantes; ii) a Otan está construindo seu poder permanente de terra, mar e aéreo, nas proximidades do território russo, juntamente com instalações de defesa de mísseis.

Perguntando se uma Otan expandida contribuiu para maior segurança ou insegurança, ele enumera as inúmeras guerras de que essa organização conduziu ou nas quais alguns de seus membros participaram: a guerra na Sérbia em 1999, que resultou na ocupação e anexação de Kosovo; as guerra do Iraque, em 2003, e da Líbia, em 2011; a guerra da Geórgia contra a Rússia, em 2008, com base na 
promessa de que o país se tornaria membro da organização; aberturas similares à Ucrânia que estão subjacentes à crise de 2014 naquele país.

Cohen inclui ainda a guerra no Afganistão, inicialmente um esforço da Otan, que teria se tornado na guerra mais longo da história americana. Por outro lado, a Otan também criou inseguranças político-ideológicas, constituindo, com seus lobbies e saturação de mídia, uma importante força condutora da guerra fria e sua crescente fobia à Rússia. Acrescentando ainda a existência de crises internas à organização não resolvidas, Coehn considera que para o bem da segurança internacional, a expansão da Nato deveria acabar. O último capítulo desta Parte III explora as razões pelas quais os russos acham que a América os está atacando.

Os textos da Parte IV vão somente até o mês de agosto de 2018 e são centrados na evolução da segunda guerra fria, finalmente reconhecida pelo establishment americano, através de um relatório emitido pelo Council on Foreign Relations. Nele, os argumentos centram-se em torno do chamado Russiagate, que trata do alegado conluio entre Putin e Trump. Os textos insistem no perigo maior dessa nova guerra fria em relação à vivida anteriormente, com o risco de uma guerra nuclear, apontam para a fobia antirrussa, incluindo uma crítica à aplicação de sanções ao país.

No curto posfácio, Cohen insiste na afirmação de que uma nova guerra fria Rússia-Estados Unidos é mais perigosa que a sua antecessora de 40 anos atrás, sobrevivida pelo mundo. Com isso, $\mathrm{CO}^{-}$ loca-se, segundo ele, a eterna pergunta, não só para os russos: "o que deve ser feito"? Baseado em pesquisa, de agosto de 2018, feita pela Gallup, na qual 58\% dos respondentes afirmaram desejar melhoria nas relações com a Rússia, Cohen considera a nova guerra fria e a expansão da Otan para o Leste como um projeto da elite. Por sua vez, uma explicação completa sobre a escolha da guerra fria incluiria as necessidades [ideológicas, de política externa, orçamentária entre outras] de um "inimigo" (aspas do autor) pelo establishment da mídia política.

Retornando à pergunta sobre o que pode ser feito, suas conclusões são pessimistas, porquanto para mudar fundamentalmente a política da guerra fria, seriam necessários líderes ainda inexistentes, embora podendo surgir inesperadamente. Nesse caso, ele pergunta: haverá tempo?

O livro foi editado em dezembro de 2018. Nos meses iniciais do ano corrente de 2019 , finalmente veio à luz o relatório de Roberto Mueller, que vinha sendo elaborado há anos, sobre o Russiagate, no qual se afirma não ter sido descoberto qualquer indício de conluio entre o presidente Donald Trump e a Rússia, através de Putin. Não cabe, aqui, discutir o desdobramento desse fato, inclusive dado o avançado das ações de Trump contra a Rússia, na forma de sanções, como modo de defender-se das acusações de conluio. Esse fato, entretanto, precisa ser ressaltado, para desvendar o papel que a nova guerra fria discutida no livro desempenhou - lamentavelmente continua desempenhando - na criação da fobia antirrussa e do demoníaco presidente Putin.

\section{Referências}

COHEN, S. F. War with Russia? From Putin \& Ukraine to Trump and Watergate. New York: Hot Books, 2018. 
WOOD, T. Russia without Putin. New

York; London: Verso, 2018.

Lenina Pomeranz é professora associada e leciona como professora sênior do Departamento de Economia da Faculdade de Economia, Administração e Contabilidade da USP. @-lenpo@terra.com.br https://orcid.org/0000-0002-45777636

${ }^{\mathrm{I}}$ Faculdade de Economia, Administração e Contabilidade, Universidade de São Paulo, São Paulo, Brasil.

Recebido em 29.4.2019 e aceito em 21.5.2019. 